\title{
Comparative Analysis of Length Differences between Georeference Surfaces
}

\author{
Borisov Mirko ${ }^{1}$, Gavrilović Milan ${ }^{1, *}$, Sladić Dubravka ${ }^{1}$, Radulović Aleksandra ${ }^{1}$, Petrović M. \\ Vladimir $^{2}$ \\ ${ }^{1}$ University of Novi Sad, Faculty of Technical Sciences, Trg Dositeja Obradovića 6, 21000 Novi Sad, \\ Republic of Serbia
}

${ }^{2}$ University of Belgrade, Institute of Chemistry, Technology and Metallurgy, Department for Ecology and Technoeconomics, Njegoševa 12, 11000 Belgrade, Republic of Serbia

*Corresponding author: Gavrilović Milan, e-mail: milangavrilovic@uns.ac.rs

\section{Abstract}

The article deals with the length differences between georeference surfaces within the state coordinate system of Serbia. It's an analysis starting from the topography, through geoid and ellipsoid, to the map projection. During the literature review, analyses of the length changes from topography to the state map projection for the geographic territory of Serbia were not found. The set of initial data consists DEM and the geoid model, as well as vector data that contain the boundary of the research area. Calculation will be performed on the basis of 88439 points of grids, located at a distance of $1 \mathrm{~km}$, while the analysis will be done by comparing average deformations, extreme deformation values, percentage of positive and negative values of deformations, as well as percentage of length without deformations. The aim of this research is to provide a set of data on length differences that covers the entire territory of Serbia.

Keywords: length differences, topography, geoid, ellipsoid, map projection.

\section{Introduction}

Study of the shape and size of the Earth according to the georeference surfaces and establishment of the reference systems from various observations are the main scientific and practical issues of geodesy, geophysics and other related disciplines (Mang et al., 2006). Recognition of the length differences for country areas mapped on the state coordinate system are very important data for many geodetic and cartographic applications. Horizontal lengths between points in physical surface of the Earth, before mapping and calculating coordinates of edges, should pass at least three different approximations, i.e. reduction from topography surface to geoid, than undulation from geoid to earth ellipsoid, and in the end projection from earth ellipsoid to map projection (Jekeli, 2012; Savrić et al., 2015; Idrizi et al., 2018).

The review and analysis of the literature did not find the study and reduction values, when moving from one georeference surface to another for Serbian territory. The objective of this research is to provide a set of data on length differences that covers the entire territory of Serbia. The calculation and comparison of data will be made by using SRTM global DEM of resolution 1" in the present study, EGM2008 model resolution 1' will be used for the geoid model, WGS84 ellipsoid and UTM map projection (Varga et al., 2013).

This paper presents the procedures, methods and technologies that are used for calculation and comparation of length differences between georeference surfaces. In adition, in relation to Serbia as a whole, differences between topography and map projection at identical points were determined and 
analysed, after the surfaces had been adjusted to the state coordinate system. Beside scientific outputs, one of the main practical results of this research is forming DEM of length differences on a grid with cells $1 \times 1 \mathrm{~km}$ covering geographical territory of Serbia.

\section{Methodology and concept of the work}

In this study, a comparison and evaluation of the characteristic of four models publicly available global referent surface were made for geographical territoty of Serbia. The referent models chosen were: SRTM, EGM2008, WGS84 and UTM map projection. On the basis of the border line, in order to create a test model that willl be used for this research, a vector network of points (Šiljeg et al., 2018) with distance of $1 \mathrm{~km}$ between them has been developed DEM for the interest of area. Before calculating the length and their differences between geodetic referential surfaces, it is necessary to calculate the value of the mean radius $\mathrm{R}$ of the reference ellipsoid, as it will appear in each subsequent equation for calculating the length (Robinson et al., 2016). Since the analysis refers to a part of the Earth, i.e. on the geographical territory of Serbia, which has relatively little extension in width, this part of the ellipsoid can be approximated by the ball. Accordingly, the mean radius $\mathrm{R}$ will be calculated according to formula by Grunter (Živković, 1972):

$\mathrm{R}=\sqrt{\mathrm{MV}}(1)$

and the radius $\mathrm{M}$ along the meridian and the radius of the first vertical $\mathrm{V}$, are calculated according to the following formulas (Kennedy et al., 2000):

$\mathrm{M}=\frac{\mathrm{a}\left(1-\mathrm{e}^{2}\right)}{\sqrt{\left(1-\mathrm{e}^{2} \sin ^{2} \varphi\right)^{3}}}(2)$

$\mathrm{V}=\frac{\mathrm{a}}{\sqrt{1-\mathrm{e}^{2} \sin ^{2} \varphi}}(3)$

with ( $\mathrm{a}=$ Equator radius, $\mathrm{e}=$ eccentricity, $\varphi=$ latitude, i.e.) parameters of ellipsoid WGS84 (Vaniček et al., 1986). For the value of the latitude that is used in these formulas, since it depends on the value of the mean radius $\mathrm{R}$, the $\varphi=44^{\circ}$ will be used, because it is a parallel that divides the geographical area of Serbia into two equal parts.

Length approximations from mean altitude between two points on the Earth surface (topography) up to the map projection is shown (Figure 1). The first linear approximation of the length is to reduce the horizontal length from the Earth surface (topography) to the surface of the geoid (sea level). The second approximation is to reduce the length from the surface of the geoid to the surface of the ellipsoid. And, the third and final approximation is the length mapping from the ellipsoid to the map projection (Idrizi et al., 2018).

\subsection{Interest area and availability of data}

As already mentioned, the work is based on the use of publicly available, i.e. open and free, datasets, and software. Based on border line obtained from Global Map Dataset (Figure 2), with the aim of creating test model to be used for that research, point vector grid with $1 \mathrm{~km}$ distance between points has been developed for geographical territory, in total with 88439 points which covers the entire area of Serbia (Figure 3).

Creation of grids, reading the necessary values from the raster as well as all other calculations were performed in MATLAB, while the cartographic presentation of the obtained results, i.e. making maps reductions were realized in ArcGIS software. Then, from the SRTM DEM and EGM2008, the geoid model, values of altitudes and geoid undulations for all points of the test model were read. 
After downloading data, and for further calculation, it is necessary to transfer all data to the UTM map projection. In this way, a DEM with spatial resolution of $30 \mathrm{~m}$ and a geoid model of resolution of $1800 \mathrm{~m}$ was obtained by ArcGIS software.

Because of their ease of use and computer efficiency, in this research of some publicly available DEMs, it was decided to use the SRTM1 Global DEM of resolution 1". For the geoid model, the EGM $2008^{2}$ model of resolution 1' will be used. By using ArcGIS software, from the SRTM Global DEM (Figure 4) and EGM08 (Figure 5), geographic coordinates, altitudes and geoid heights for all 88439 points of test model have been extracted.

By analyzing datamodel SRTM Global DEM, we can see that altitudes of DEM for the geographical territory of Serbia range from $21 \mathrm{~m}$ to $2651 \mathrm{~m}$ (Figure 4), with an average height of $463 \mathrm{~m}$. While the geoid model of EGM08 valations range from $42 \mathrm{~m}$ to $47 \mathrm{~m}$ (Figure 5), and their mean value is $45 \mathrm{~m}$.

\subsection{Calculation and comparison length differences}

The process of calculation and comparison of length differences from topography to map projection within the state coordinate system was carried out in next phases:

1. Calculation of $1 \mathrm{~km}$ length differences and comparison between topography (SRTM) and geoid (EGM08), as well geoid and reference ellipsoid (WGS84);

2. Calculation of $1 \mathrm{~km}$ length differences and comparison between topography (SRTM) and ellipsoid (WGS84), as well ellipsoid (WGS84) and map projection (UTM);

3. Calculation of $1 \mathrm{~km}$ length differences and comparison between topography (SRTM) and map projection (UTM).

\subsubsection{Differences between topography and geoid, as well geoid and ellipsoid}

The first in a series of length differences that is calculated is the difference of $1 \mathrm{~km}$ of length between the topographical surface and the geoid (Figure 6). It is calculated according to the following formula (Varmeer, 2016):

$D_{g}=D \cdot \frac{R+N}{R+N+H}(4)$

From the calculated values of the lengths on the geoid, the reduction value ranges from -0.439 $\mathrm{cm} / \mathrm{km}$ to $-39.342 \mathrm{~cm} / \mathrm{km}$ while the mean reduction value is $-7.198 \mathrm{~cm} / \mathrm{km}$. From the calculated reductions for all 88439 points of the test model, a vector network is formed and from it raster was made with a spatial resolution of $1 \mathrm{~km}$ (Figure 6).

From this raster, we see that at least the reduction values are arranged in the plain field, i.e. in north part territory of Serbia (exception is the mountain Fruška Gora) and in the area around the rivers Great, Western and Southern Morava, and the highest values are found at places of great altitudes on mountains (Prokletije, Kopaonik, Zlatibor, Stara planina). This is a clear indication that the altitude greatly affects the value of the reduction, so that on flat terrain the values of this reduction are so small that they can be neglected, while in places with higher altitude differences the value of this reduction reaches several decimeters, so it must be taken into account when computing (Heiskanen et al., 1967).

\footnotetext{
${ }^{1}$ https://earthexplorer.usgs.gov/

${ }^{2}$ http://earth-info.nga.mil/GandG/wgs84/gravitymod/egm2008/egm08_wgs84.html
} 
In the second step (Figure 7), the lenght difference between the geoid and the surface of the ellipsoid is calculated according to the following formula (Varmeer, 2016; Tziavos et al., 2013):

$\mathrm{S}=\mathrm{D}_{\mathrm{g}} \cdot \frac{\mathrm{R}}{\mathrm{R}+\mathrm{N}}(5)$

From the calculated length values and the difference of these lengths with the corresponding lengths on the geoid, we see that the extreme reduction values in range from $-0.651 \mathrm{~cm} / \mathrm{km}$ to $-0.733 \mathrm{~cm} / \mathrm{km}$, with a mean reduction value of $-0.707 \mathrm{~cm} / \mathrm{km}$. As the geoid in the whole geographical territory of Serbia is above the ellipsoid (Odalović, 2010), all the reductions are also with a negative prefix.

\subsubsection{Differences between topography and ellipsoid, as well ellipsoid and map projection}

The next difference is between the length on the topographic surface and the ellipsoid (Figure 8). It is calculated according to the following formula (Varmeer, 2016; Torge, 2001):

$\mathrm{S}=\mathrm{D} \cdot \frac{\mathrm{R}}{\mathrm{R}+\mathrm{N}+\mathrm{H}}(6)$

The range of these differences varies from $-1.141 \mathrm{~cm} / \mathrm{km}$ to $-40.060 \mathrm{~cm} / \mathrm{km}$, while the mean reduction value is $-7.904 \mathrm{~cm} / \mathrm{km}$.

Serbian state map projection is UTM projection. It is defined with the following parameters (Kennedy et al., 2000; Jovanović, 1983):

- UTM zone $34 \mathrm{~N}$;

- Central meridian $21^{\circ}$;

- Scale factor 0.9996;

- False easting $500000 \mathrm{~m}$.

The scale factor of UTM projection is 0.9996 on the middle meridian, but with the distance from the middle meridian it is variable, and it is calculated according to the following formula (Kennedy et al., 2000; Jovanović, 1983):

$\mathrm{C}=0.9996+\frac{\mathrm{Y}^{2}}{2 \mathrm{R}^{2}}+\frac{\mathrm{Y}^{4}}{24 \mathrm{R}^{4}}(7)$

where $\mathrm{Y}$ is ordinate on the plane of projection and $\mathrm{R}$ is mean radius of the ellipsoid.

By calculating the lengths in the projection, and the differences of these lengths with the same ellipsoid, we see that the deformation values varies from $-5.300 \mathrm{~cm} / \mathrm{km}$ to $-40.000 \mathrm{~cm} / \mathrm{km}$, and the mean value of this deformation is $-32.844 \mathrm{~cm} / \mathrm{km}$. Based on these deformations, a raster with resolution of $1 \mathrm{~km}$ was created (Figure 9) where the boundary between the adjacent intervals is clearly visible, and that the deformations by the same latitude are the same for the same meridian, i.e. for the same longitude. It is also clearly noticed that the largest values of the differences in these lengths are grouped around the middle meridian, which was expected because the deformations in the UTM projection are greatest along the middle meridian.

\subsubsection{Differences between topography and map projection}

The final step is to calculate the reduction of $1 \mathrm{~km}$ of horizontal length from the topographic surface to the plane of the projection. From the obtained results we can see that the reduction values vary from $-7.313 \mathrm{~cm} / \mathrm{km}$ to $-80.048 \mathrm{~cm} / \mathrm{km}$, with the mean reduction value of $-40.748 \mathrm{~cm} / \mathrm{km}$. Here we note that all reductions are negative, which means that all transition of lengths from the topography 
to the plane of the projection will be reduced, and that the entire national surface will reduce the surface after transitioning from topography to the plane of projection.

From the raster in Figure 10, which, like all previous ones, was made in a resolution of $1 \mathrm{~km}$, it can be seen how different reductions affect the change in length, depending on the elevation characteristics of the terrain.

\section{Results and discussion}

The final results of all reductions (deformations) for the geographical territory are shown in Table 1, which shows the extreme values, the mean values, the percentage of positive and negative deformations, and the percentage of length without deformations between topography, geoid, ellipsoid and map projection.

Namely, all the reductions have a negative sign and accordingly the lengths will be reduced by moving from one surface to another, going from the topographic surface to the projection plane. What is more interesting from Table 1 is that the value of the average reduction for all points significantly deviates from the extreme values in the reductions for the transition from the topographic surface to the geoid, as well as in the reduction for the transition from the ellipsoid to the projection plane, and with reduction to reduce lengths from a topographic surface to an ellipsoid and from a topographic surface to a projection plane.

We can see that the largest length reductions (deformations) occur when transitioning from the topography to the map projection (Figure 11). But this reduction, as well as those for reducing the length from the topographic surface to the ellipsoid, is not so interesting for further analysis, because in order to move from the topography to the projection, i.e. to the ellipsoid, it must be transitioned over the ellipsoid, i.e. geoid, and therefore by observing these overall reductions, it is not clear what is happening between these surfaces (Vaniček et al., 2012; Pavlis et al., 2012).

This is precisely why Figure 12 is given showing the percentage of three reductions between two adjacent surfaces in the total reduction to reduce the length from the topographic surface to the projection plane.

It is clear that the greatest impact, of $80 \%$, on the overall horizontal length repair is the reduction that is added when it moves from the ellipsoid to the projection plane. The smallest impact on the overall reduction is the repair that must be added to the length when one wants to move from geoid to ellipsoid.

Also from the histograms (Figure 13) it can be see that the reductions are grouped around the mean, with the largest number being in the range from $-41.499 \mathrm{~cm} / \mathrm{km}$ to $-42.226 \mathrm{~cm} / \mathrm{km}$. Here, too, we notice that all reductions are negative, which means that all lengths will be reduced by moving from the topography to the projection plane, and that the entire national surface will be reduced after the transition from the topography to the projection plane.

In the central and southern parts of Serbia, the change in length is the most expressed effect of reduction for the transition from the topography to the ellipsoid, due to the fact that in this part, the height difference between this two surfaces is largest, it is clear that the reductions at that location will have the highest values. But in the northwest area of Serbia, the situation is different, and it is clearly seen that the greatest influence on the length deformation has a reduction in reducing the length from the ellipsoid to plain projection, which is due to very small changes in the height of the points on the Earth's surface, deviations from this rule occur in the area of the mountain Fruška Gora, which with its height significantly deviates from the surrounding plain terrain. 


\section{Conclusion}

The comparison of data from the obtained results in comprehensive analyzes of length differences between georeference surfaces for the geographical territory of Serbia, we can carry out several important observations. The first thing we notice is that the smallest reduction value, both in the entire geographical territory of Serbia and in every part of it, is the transition from geoid to ellipsoid. Also, the value of this reduction is very similar to all four analyzed cases. This small and for all parts of the territory similar reduction values, stem from the fact that the geoid has a relatively low height above the ellipsoid, as well as small changes occur in the relative heights of the points on the geoid.

The next observation refers to the highest reduction values obtained by reducing the length from the ellipsoid to flat projection. As for the smallest reduction values, and here the situation is the same, i.e. this reduction is dominant in all four analyzed cases. This phenomenon is somewhat expected, given that the UTM map projection deformations are greatest on the central meridian, which divides the geographical territory into two approximately equal parts. So in this part deformations that occur are $-40 \mathrm{~cm} / \mathrm{km}$ for all analyzed territories. As the cylinder in the UTM map projection cuts the ellipsoid in the 18th and 24th of the meridian on the territory, there will be no deformations in the transition from ellipsoid to flat projection, which confirmed the results.

Also, we can see that the selection of the site does not significantly affect the length reduction from the geoid to the ellipsoid, because the geoid does not have a major change in value in the territory. The situation is different with the reduction for the transition from the topography to the geoid, since greatest effect on reduction are the height difference between the endpoints of the measured length. So we can see that the smallest changes in length occur on the north part, while the biggest ones appear on the south part of the territory. For length reduction by transitioning from the ellipsoid to the map projection, the highest value occur in southwest part of the territory. The main reason is the centralization of the geographical territory above the central meridian and a small longitude, and the smallest reduction value is noticeable in the north territory of Serbia. The reason for the lower values of this reduction in the nortwest territory is the movement in relation to the central meridian and the approach to the meridian that cuts the Earth's cylinder.

Finally, it should be noted that the accuracy of the obtained results depends on the accuracy of the used data, i.e. from the accuracy of the digital elevation model and the accuracy of their calculation depends on the accuracy of used surfaces.

\section{References}

[1] Mang, R., Haussler, H. (2006). International Handbook Military Geography, Ministry of Defence, Vienna, Österreich.

[2] Jekeli, C. (2012). Geometric Reference Systems in Geodesy, Ohio State University, USA.

[3] Savrić, B., Jenny, B., White, D., Strebe, D. (2015). User preferences for world map projections, Cartography and Geographic Information Science, Vol. 42, No. 5, pp. 398 - 409., doi: https://doi.org/10.1080/15230406.2015.1014425.

[4] Idrizi, B., Pashova L., Kabashi, I., Mulić, M., Krdzalić, Dz., Tutić, D., Vucetić, N., Kevic, K., Nikolić, G., Djurović, R. (2018). Study of length differences from topography to map projection within the state coordinate systems for some countries on the Balkan Peninsula, FIG 2018, Istanbul, Turkey. 
[5] Varga, M., Bašić, T. (2013). Quality assessment and comparison of global digital elevation models for Croatia, Cartography and Geoinformation, N0. 20, Vol. 12, pp. 5 - 17, Zagreb, Croatia.

[6] Šiljeg, A., Barada, M., Marić, I. (2018). Digitalno modeliranje reljefa, Sveučilište u Zadru, Croatia.

[7] Robinson, A.; Morrison, J.; Muehrcke, P.; Kimerling, A.; Guptill, S. (2016). Elements of Cartography, Sixth Edition, USA.

[8] Živković, A. (1972). Viša geodezija, Gradjevinska knjiga, Belgrade, Serbia.

[9] Kennedy, M., Kopp S. (2000). Understanding Map Projections, Environmental Systems Research Institute (ESRI), Redlands, USA.

[10] Vaniček, P., Krakiwsky, E. (1986). Geodesy: The concepts. Elsevier Science, Amsterdam, The Netherlands.

[11] Varmeer, M. (2016). Physical geodesy, University of Technology, Helsinki, Finland.

[12] Heiskanen, W., Moritz, H. (1967). Physical Geodesy. Book, San Francisco: W.H. Freeman and Co., USA.

[13] Tziavos, I., Sideris, M. (2013). Topographic Reductions in Gravity and Geoid Modeling. In Sansò F. (Ed.), Sideris M. (Ed.), Geoid Determination, pp. 337 - 400. Berlin: Springer. doi: https://doi.org/10.1007/978-3-540-74700-0_8.

[14] Odalović, O. (2010). Fizička geodezija, Gradjevinska knjiga, Belgrade, Serbia.

[15] Torge, W. (2001). Geodesy, Walter de Gruyter, Berlin - New York, USA.

[16] Jovanović, V. (1983). Matematička kartografija, Book, Vojnogeografski institut, Belgrade, Serbia.

[17] Vaniček, P., Kingdon, R., Santos, M.(2012). Geoid versus quasigeoid: a case of physics versus geometry, Contributions to Geophysics and Geodesy, Vol. 42, No. 1, pp. 101 - 117., USA.

[18] Pavlis, N., Holmes, S., Kenyon, S., Factor, J. (2012). The development and evaluation of the Earth Gravitational Model 2008 (EGM2008), Journal of geophysical reseach, Wiley, https://doi.org/10.1029/2011JB008916

Table 1. Deformations of $1 \mathrm{~km}$ length in the state coordinate system of Serbia

\begin{tabular}{|l|c|c|c|c|c|}
\hline & $\begin{array}{c}\text { SRTM - } \\
\text { EGM08 }\end{array}$ & $\begin{array}{c}\text { EGM08 - } \\
\text { WGS84 }\end{array}$ & $\begin{array}{c}\text { SRTM - } \\
\text { WGS84 }\end{array}$ & $\begin{array}{c}\text { WGS84 - } \\
\text { UTM34N }\end{array}$ & $\begin{array}{c}\text { SRTM - } \\
\text { UTM34N }\end{array}$ \\
\hline Average deformations [cm/km] & -7.198 & -0.707 & -7.904 & -32.844 & -40.748 \\
\hline Min deformations [cm/km] & -39.342 & -0.733 & -40.060 & -40.000 & -80.048 \\
\hline Max deformations [cm/km] & -0.439 & -0.651 & -1.141 & -5.300 & -7.313 \\
\hline Without deformations [\%] & 0 & 0 & 0 & 0 & 0 \\
\hline Positive deformations [\%] & 0 & 0 & 0 & 0 & 0 \\
\hline
\end{tabular}




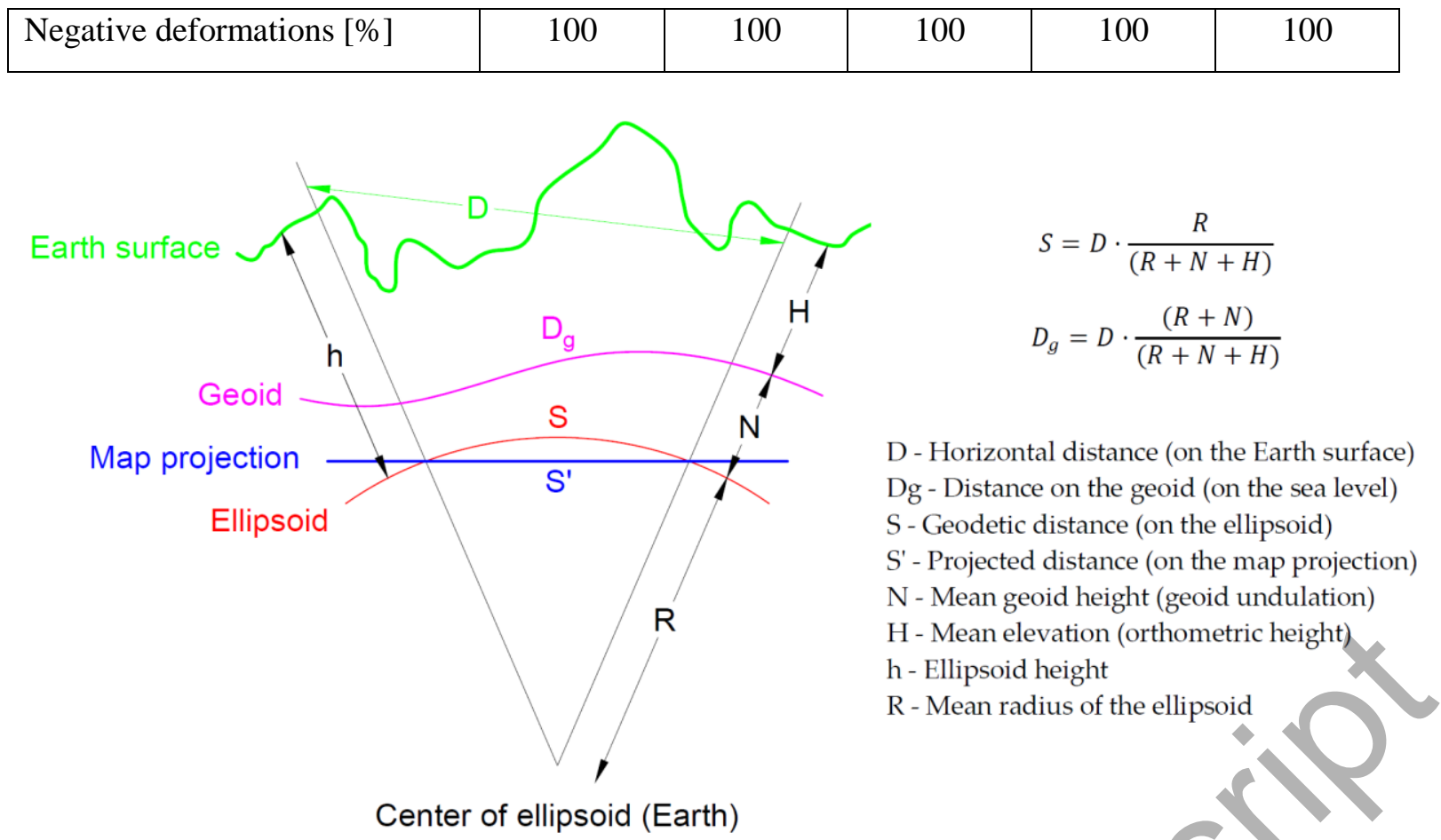

Figure 1. Georeference surfaces (Earth surface, geoid, ellipsoid and map projection)
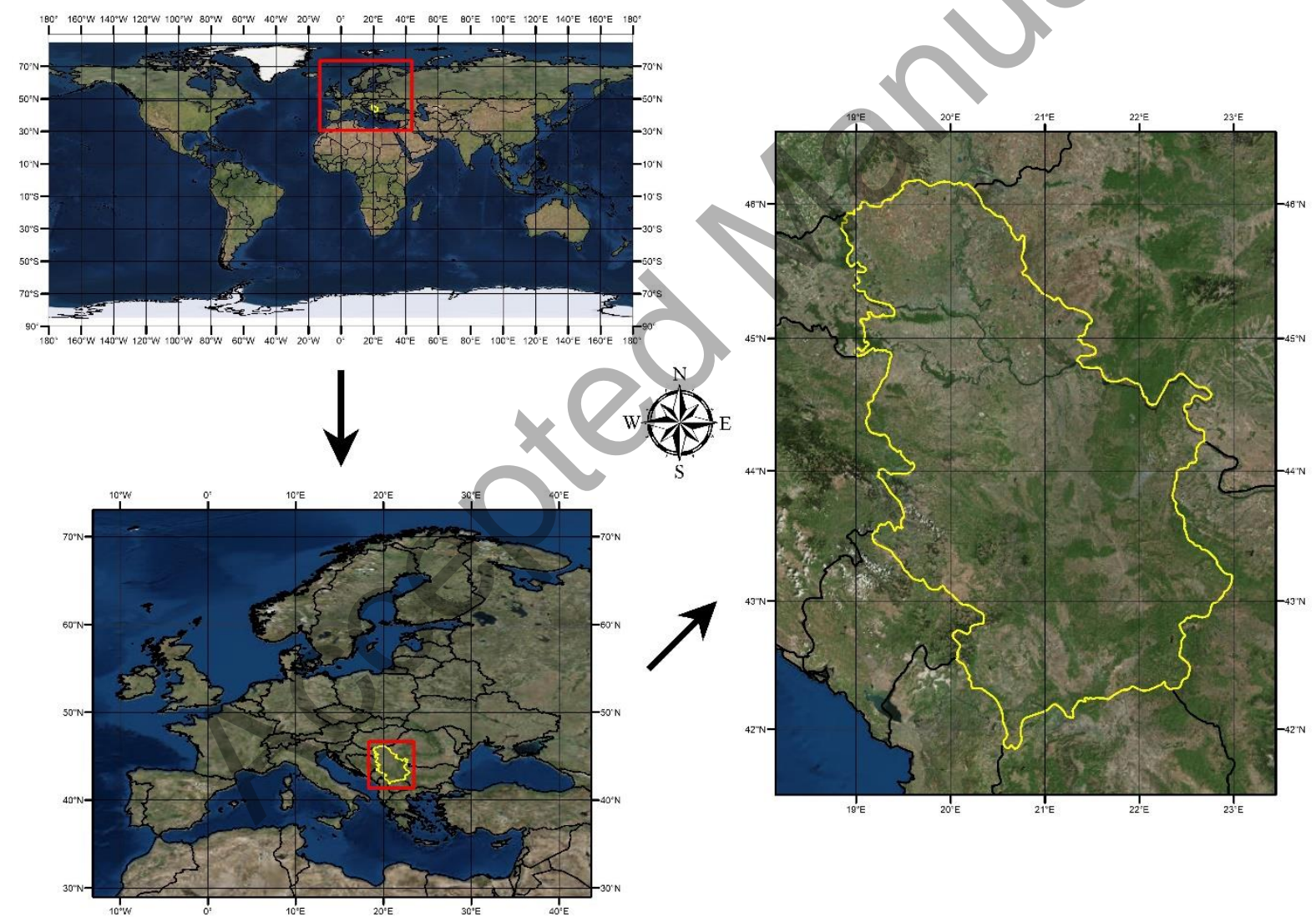

Figure 2. Position and territory of Republic of Serbia 


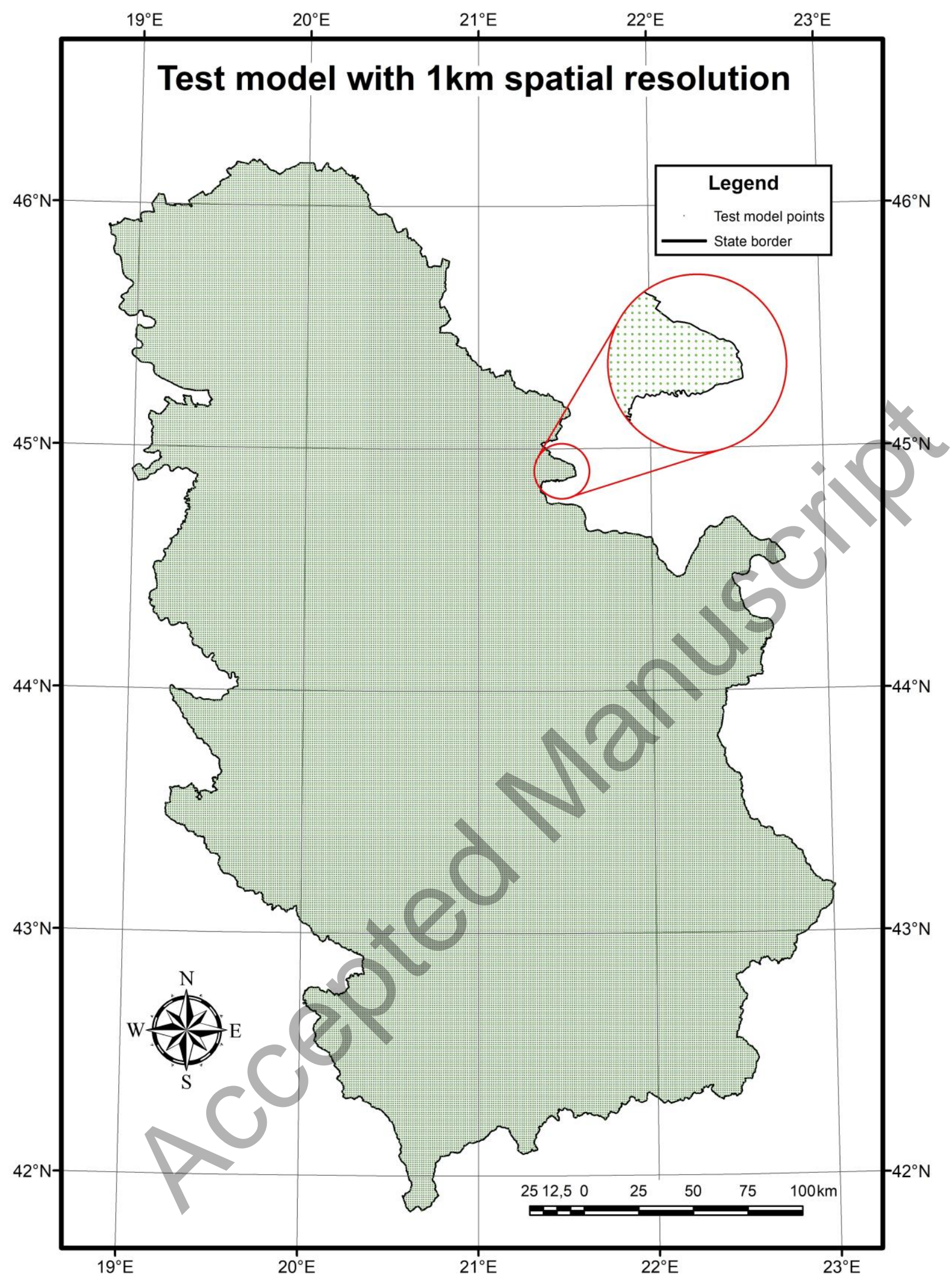

Figure 3. Test model with $1 \mathrm{~km}$ spatial resolution 


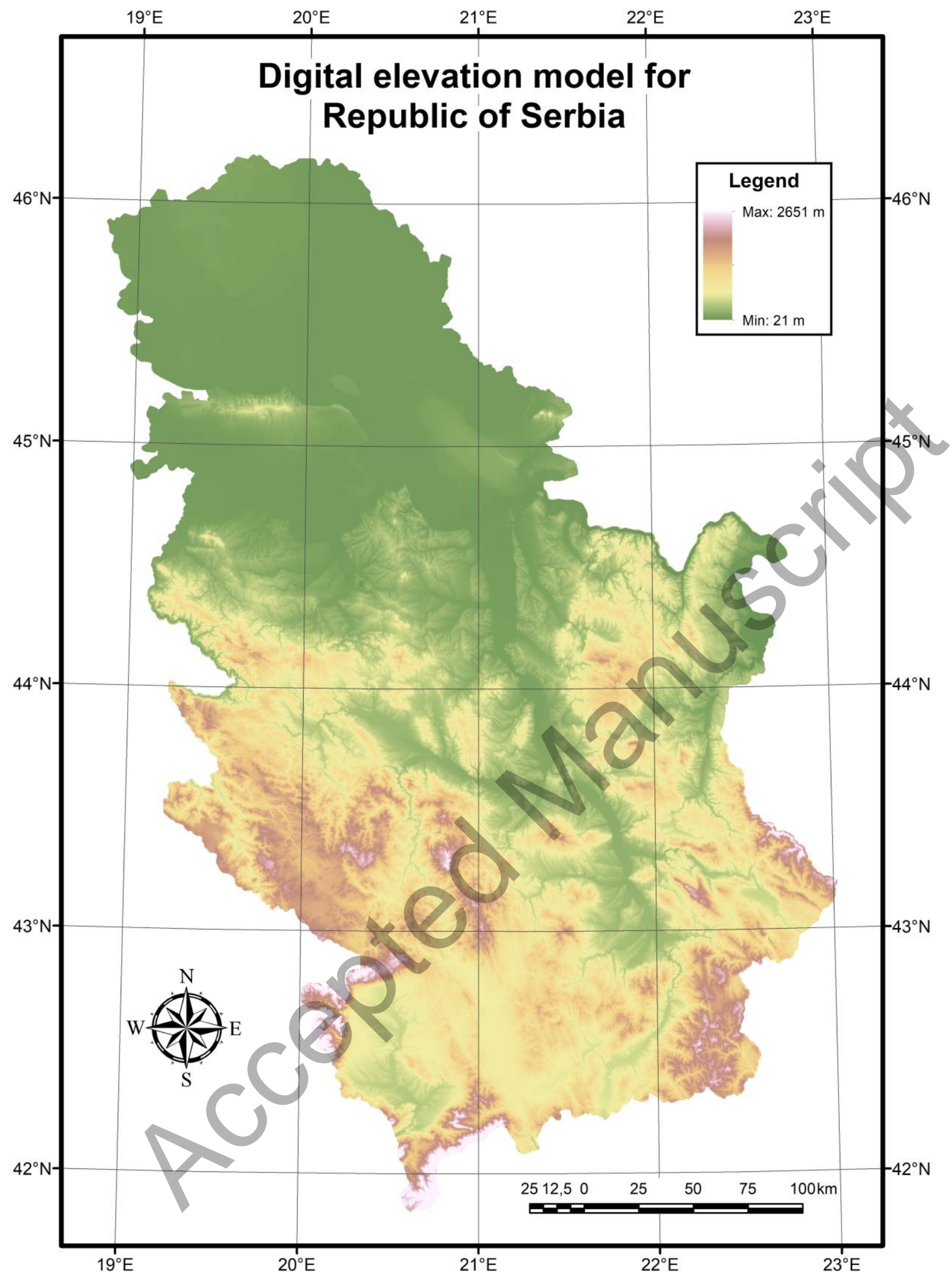

Figure 4. SRTM Global DEM - topography 


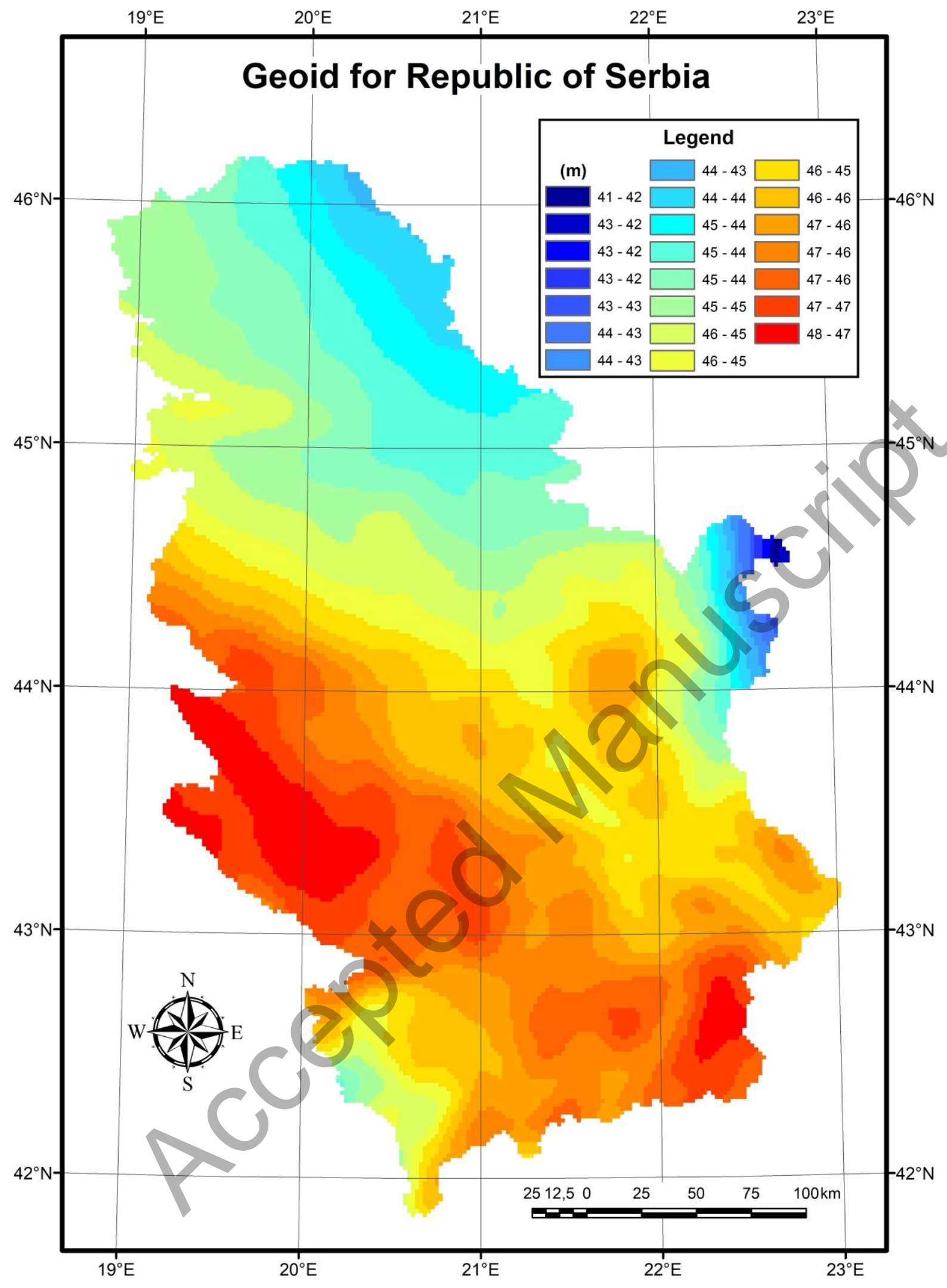

Figure 5. Geoid model of EGM08 


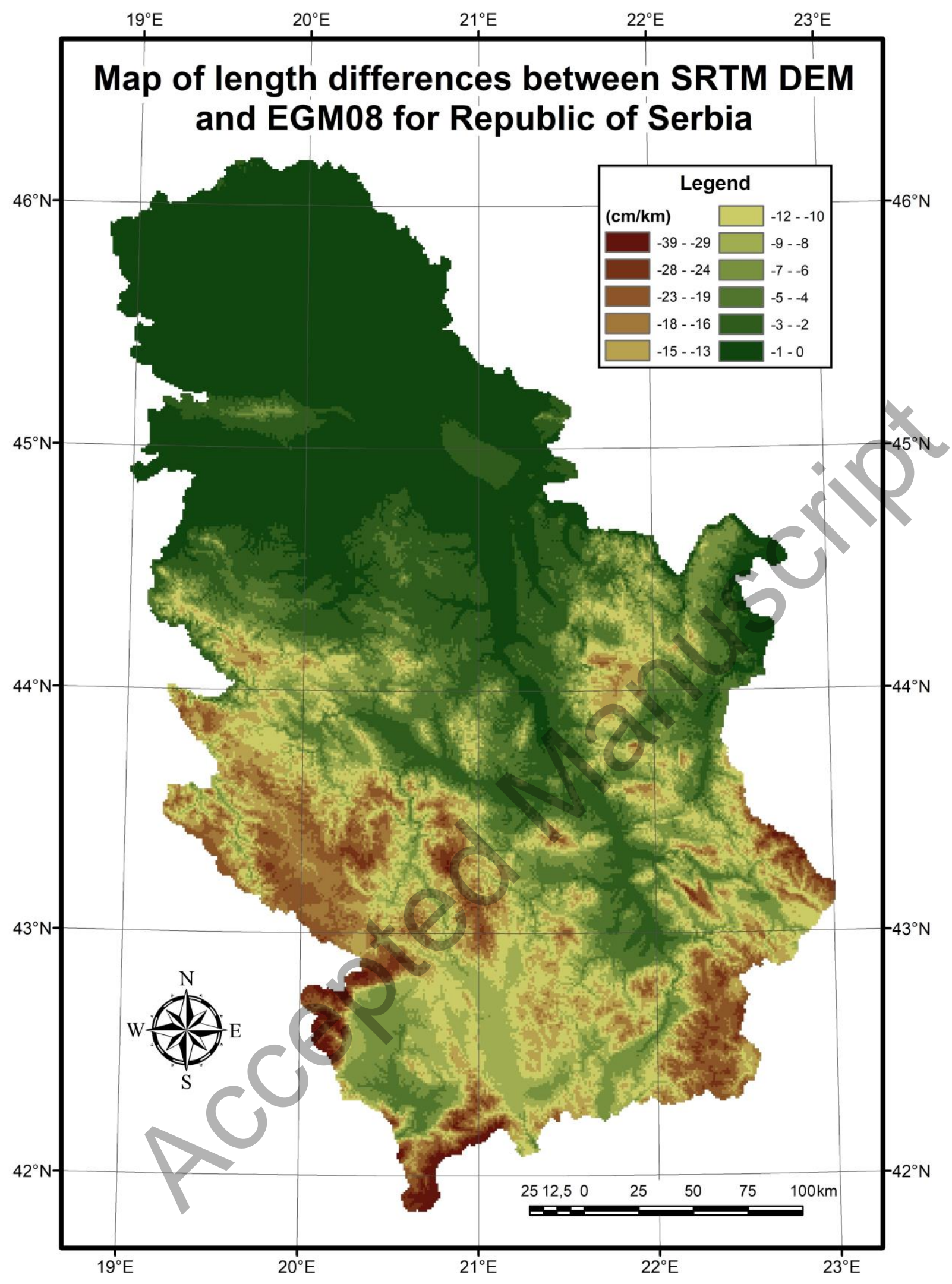

Figure 6. Length differences of $1 \mathrm{~km}$ between topography and geoid 


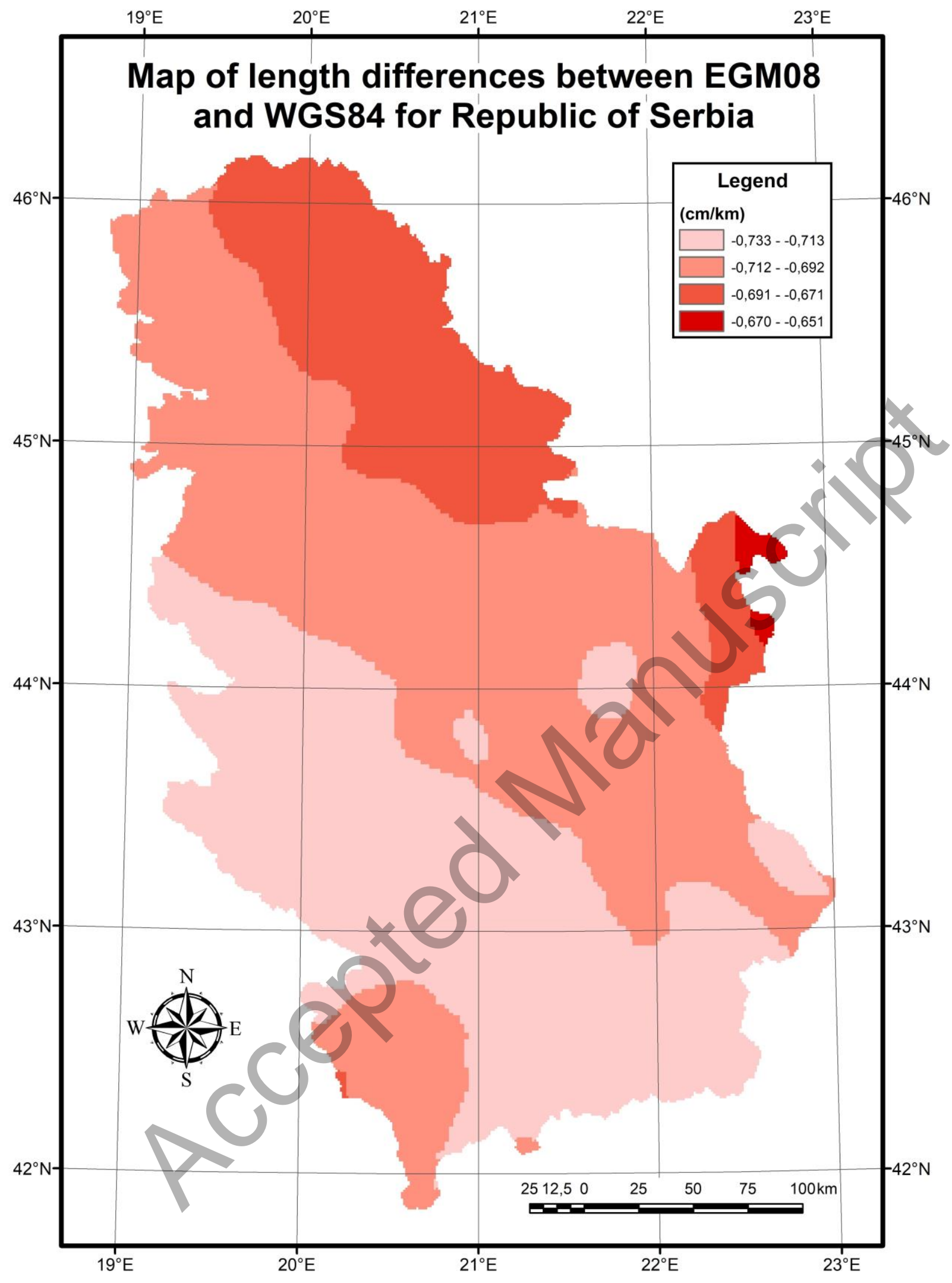

Figure 7. Length differences of $1 \mathrm{~km}$ between geoid and WGS84 ellipsoid 


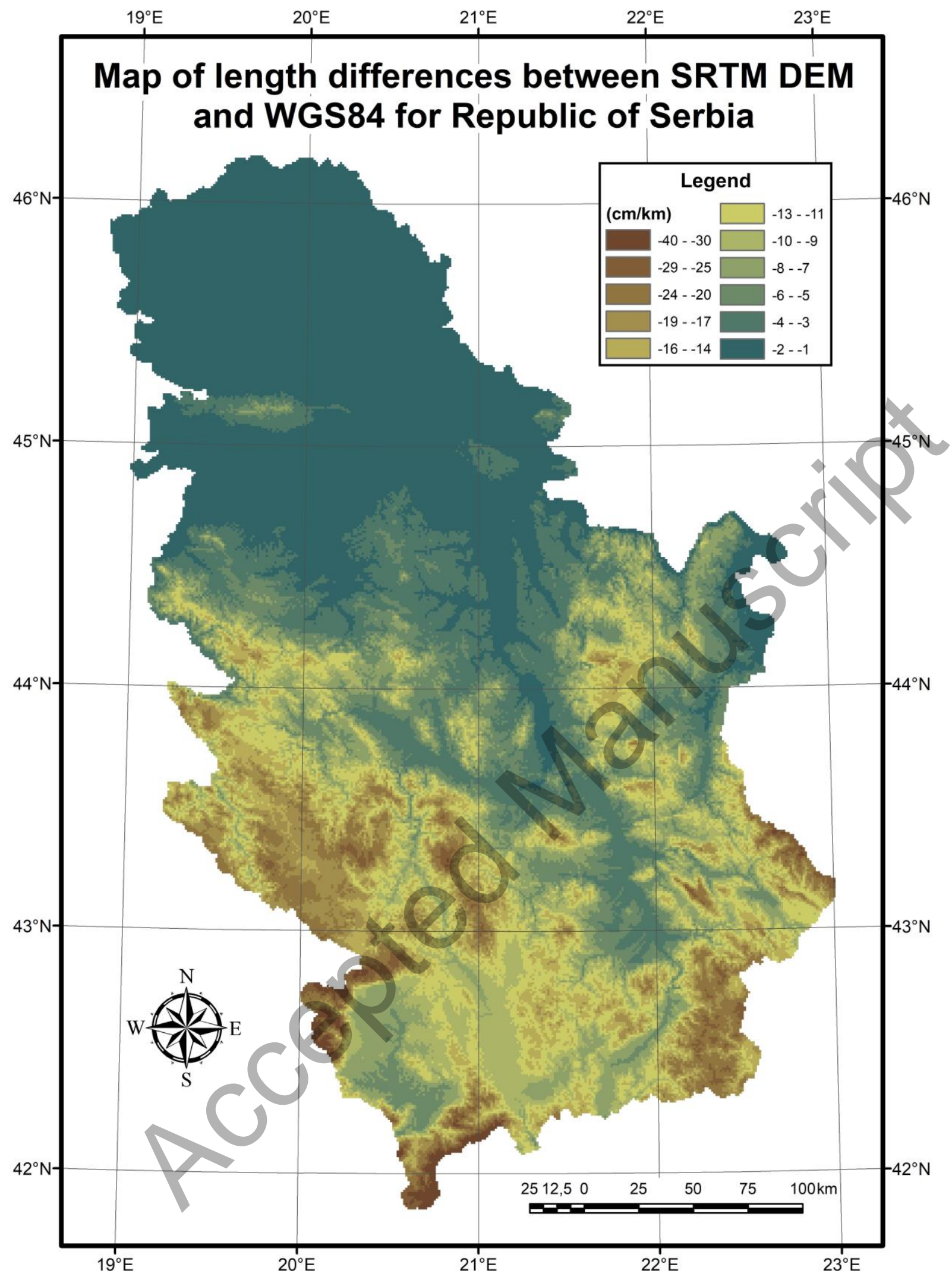

Figure 8. Length differences of $1 \mathrm{~km}$ between topography and WGS84 ellipsoid 


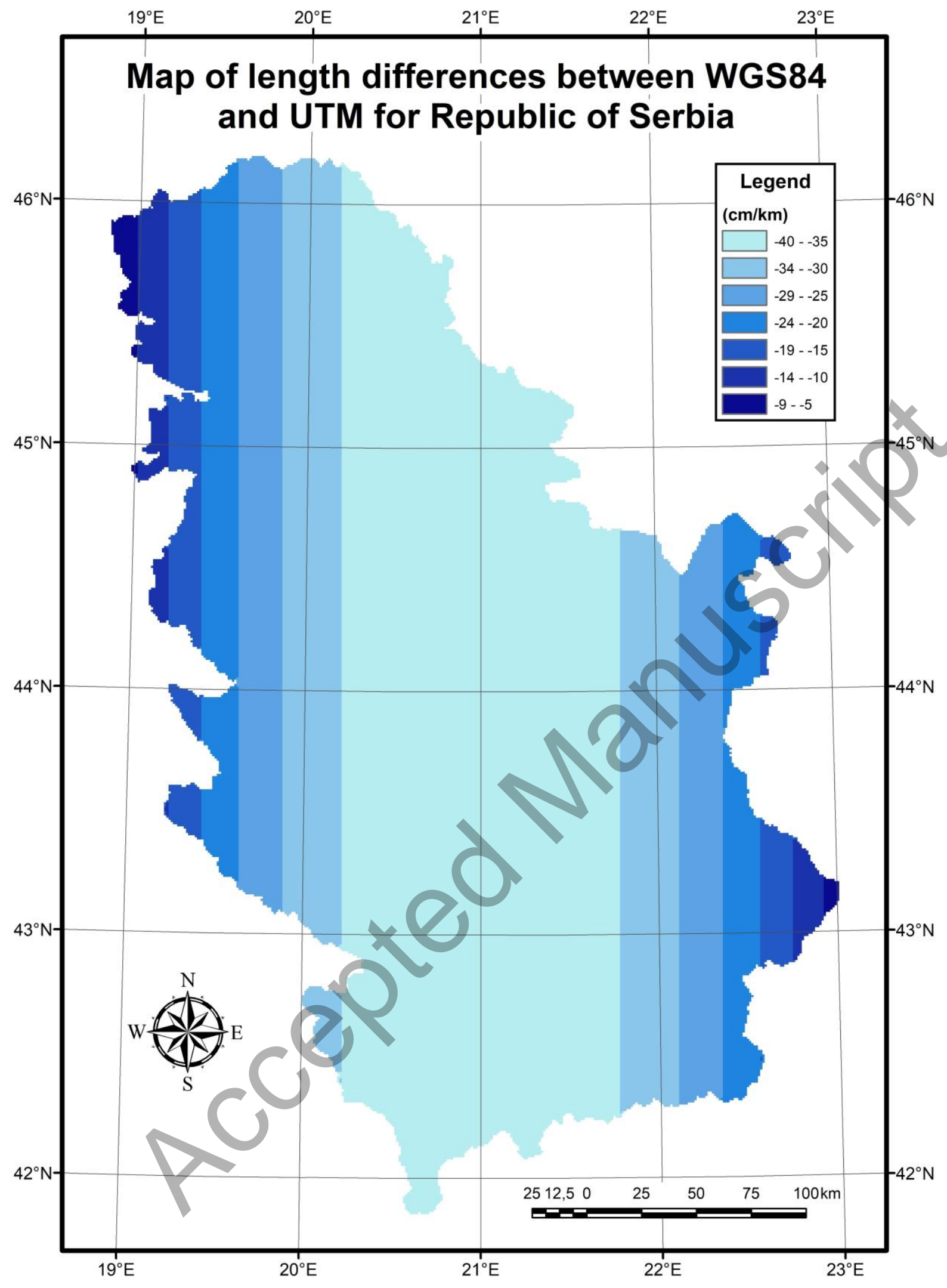

Figure 9. Length differences of $1 \mathrm{~km}$ between WGS84 ellipsoid and UTM projection 


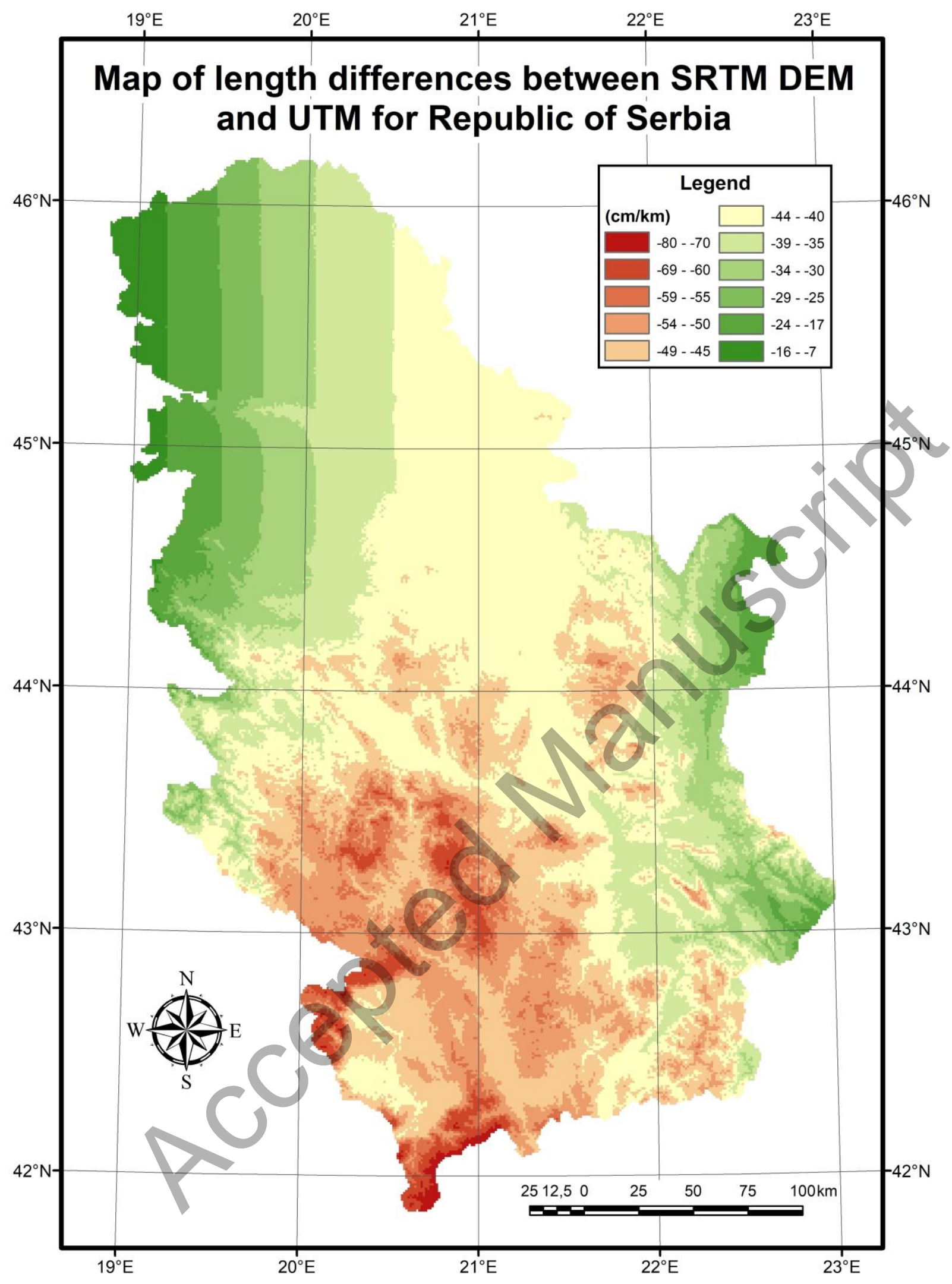

Figure 10. Length differences of $1 \mathrm{~km}$ between topography and UTM map projection 


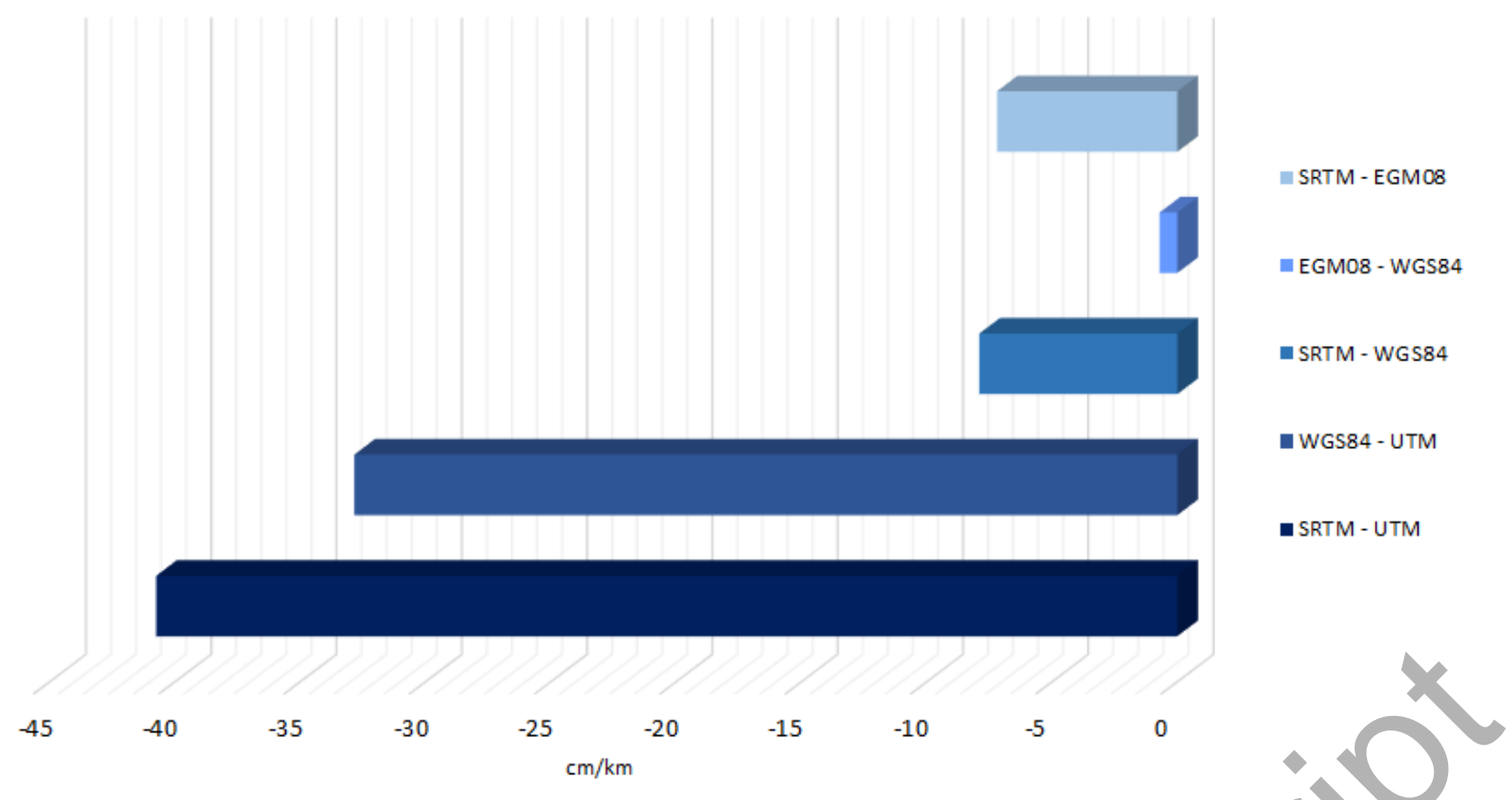

Figure 11. Graphical representation of reductions of $1 \mathrm{~km}$ horizontal length for Serbian territory

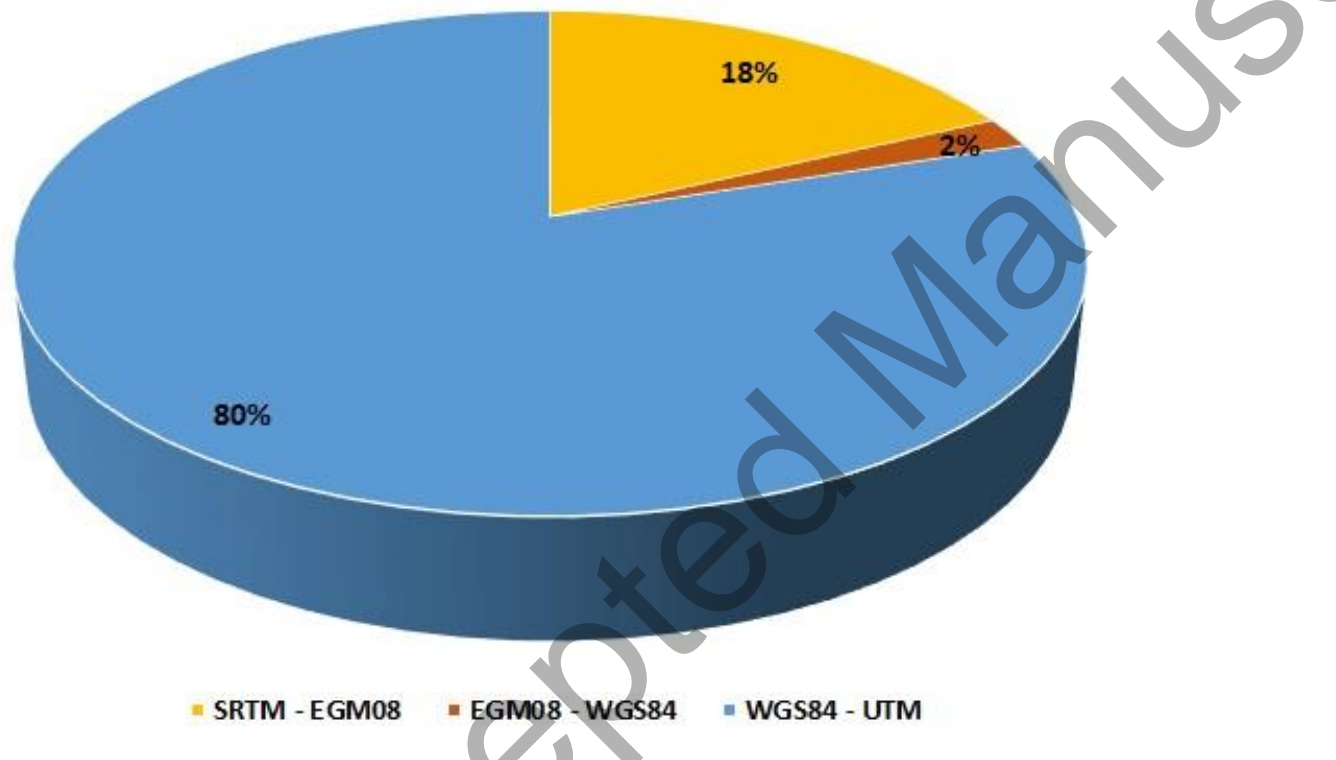

Figure 12. Percentage of individual repair in the total mean reduction value for reducing the length from the topography to the map projection 


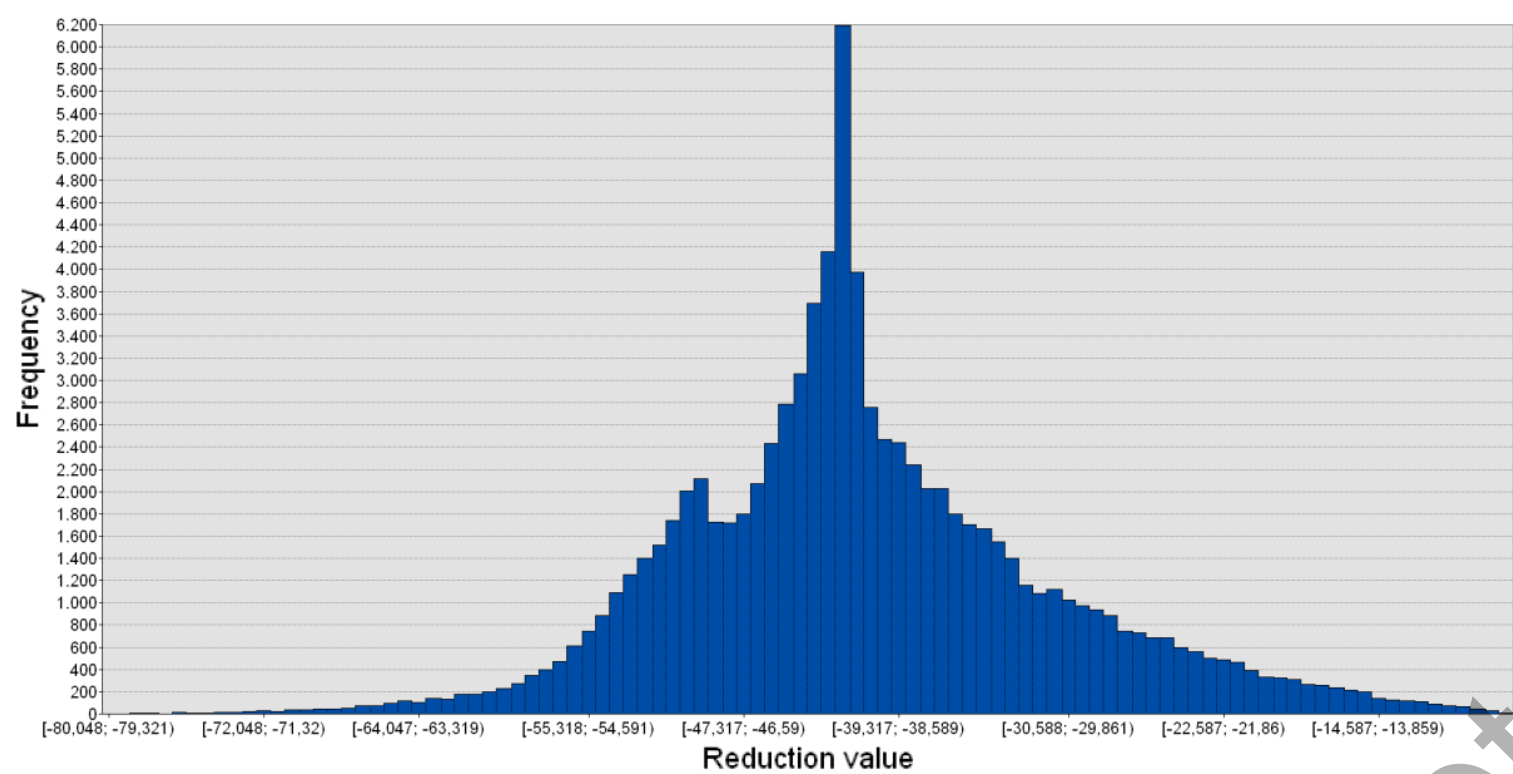

Figure 13. Histogram of reductions lengths from topography to map projection 